\title{
Knowledge Mapping of Acupuncture for Cancer Pain: A Scientometric Analysis (2000-2019)
}

This article was published in the following Dove Press journal: Journal of Pain Research

\section{Li Huang* \\ Yanqing Zhao (D)* \\ Minhong Xiang}

Putuo Hospital, Shanghai University of Traditional Chinese Medicine, Shanghai, People's Republic of China

*These authors contributed equally to this work
Correspondence: Minhong Xiang

Putuo Hospital, Shanghai University of

Traditional Chinese Medicine, 164 Lanxi

Road, Putuo District, Shanghai, 200062,

People's Republic of China

Tel +86 I3023200090

Email xiangminhong1977@I26.com
Objective: This study aimed to demonstrate the state of the present situation and trends concerning the global use of acupuncture for cancer pain in the past 20 years.

Methods: Searched the Web of Science database from 2000 to 2019 related to acupuncture for cancer pain, and then used CiteSpace to conduct scientometric analysis to acquire the knowledge mapping.

Results: Yearly output has increased year by year, and the growth rate has become faster after 2012. According to the cluster analysis of institutions, authors, cited references, and keywords, 4, 4, 15, and 14 categories were obtained, respectively. The most productive countries, institutions, and authors are the USA, Mem Sloan Kettering Cancer Center, and Mao JJ, whose frequencies are 196, 24, and 17, respectively. However, the most important of them are Australia, Univ. Maryland, and Bao T, owing to their highest centrality, they are $0.90,0.21$, and 0.09 separately. Moreover, cited references that contributed to the most cocitations are Crew KD (2010), however, the most key cited reference is Roscoe JA (2003). Keywords such as acupuncture, pain, breast cancer, palliative care, and quality of life are the most frequently used. But auricular acupuncture is the crucial keyword. In the cluster analysis of institutions, authors, cited references, and keywords, the more convincing research categories are multiple myeloma, placebo effect, neck malignancies, and early breast cancer, with $\mathrm{S}$ values of $0.990,0.991,0.990$, and 0.923 , respectively. Therefore, they can be regarded as research hotspots in this field.

Conclusion: Based on the scientometric analysis in the past 20 years, the knowledge mapping of the country, institution, author, cited reference, and the keyword is gained, which has an important guiding significance for quickly and accurately positioning the trend in this field.

Keywords: knowledge mapping, acupuncture, cancer pain, CiteSpace, scientometric analysis

\section{Introduction}

Cancer is the main cause of death that endangers human health in the world. Due to population growth and accelerated aging, the various burdens brought by cancer will gradually increase. ${ }^{1}$ Pain is a distressing symptom experienced by more than $70 \%$ of cancer patients. ${ }^{2}$ According to reports, about $25 \%$ of newly diagnosed cancer patients, $33 \%$ of patients receiving anti-cancer treatment, and $75 \%$ of advanced cancer patients have varying degrees of pain. ${ }^{3}$ The vast majority of confirmed patients are from middle- and low-income countries. Among lowincome people, cancer pain patients face additional challenges brought about by infection and poverty. These problems make cancer and cancer pain more 
complicated. ${ }^{4}$ The three-step analgesic ladder adopted by the World Health Organization is effective in the treatment of cancer pain, ${ }^{5}$ but analgesics have many adverse reactions, such as nausea and constipation. ${ }^{6}$ Therefore, to relieve the adverse drug reactions of cancer pain and the huge economic burden caused by the treatment process, it is urgent to find a suitable alternative treatment plan. Acupuncture is regarded as one of the non-drug therapies to relieve pain and improve function due to its low side effects. This is recognized in the National Comprehensive Cancer Network (NCCN) guideline. ${ }^{7}$

Scientometrics is an interdisciplinary science that uses mathematical and statistical methods to quantitatively analyze all knowledge carriers. It provides a reliable method for researchers to deeply understand the study in this field, including the analysis of different databases, such as Web of Science, ${ }^{8}$ Pubmed, ${ }^{9}$ Scopus, ${ }^{10}$ Derwent, ${ }^{11}$ etc. Among them, Web of Science is the most common, there is also analysis using different software, for instance: CiteSpace, ${ }^{12}$ VOSviewer, ${ }^{13}$ Histcite, ${ }^{14}$ etc. can be used for scientometric analysis. Using CiteSpace and VOSviewer software as tools to carry out scientometric research occupies the vast majority, and its application scope also covers many fields. In the form of a knowledge map, readers can vividly understand the frontiers, hotspots, and trends of the field, which helps us to clarify the development context of a certain research field. ${ }^{15}$ CiteSpace is an information visualization software developed by the Java language. ${ }^{16}$ It is used to measure the literature in a specific field to explore the key path and knowledge turning points of the evolution for the subject field. CiteSpace includes co-citation, co-author, and cooccurrence analysis, ${ }^{17}$ which is of great benefit to the construction of scientific research cooperation networks and co-occurrence analysis of topics and fields. Then, the three concepts of betweenness centrality, burst detection, and heterogeneous network help identify research frontiers, tag keywords, identifying emerging trends, and sudden changes over time. ${ }^{18}$ Therefore, the scientometric analysis of acupuncture for cancer pain through CiteSpace can not only obtain the research trend but also gain knowledge mappings such as cluster views and timeline graphs, which is of great significance for young scholars who will be engaged in research in this field to accurately grasp the research direction.

To date, there has been no comprehensive article of studies on acupuncture for cancer pain using bibliometric methods. Therefore, in this study, to analyze the global status and trend of acupuncture for cancer pain in the past 20 years, the researchers used CiteSpace to analyze the relevant literature in the web of Science Database (SCI-E) from 2000 to 2019, so as to construct the knowledge map of this field.

\section{Methods \\ Source of Literature}

To prevent the omission of searching the literature, we use "acupuncture" to search for synonyms in the MeSH Database, the subject word database in Pubmed, and then merge the final data. At the same time, search for synonyms of "cancer", mainly including carcinoma, neoplasm, and tumor. Firstly, we input the Web of Science database with English Subject words= "cancer" OR "tumor" OR "carcinoma" OR "neoplasm", and TS= "pain", and TS= "acupuncture" OR "Acupuncture Therapy" OR "Acupuncture, Ear" OR "Acupuncture Points" OR "Acupuncture Analgesia", 19 respectively. Next is Web of Science database settings: literature was retrieved online through the Science Citation Index-Expanded of the Web of Science Core Collection on October 25, 2020, ${ }^{20}$ and the language of the literature is not limited. The search range of the database is 2000-2019, it analyses on this basis. After literature retrieval, a total of 1095 records were obtained, and 504 pieces of literature were used for scientometric analysis after CiteSpace removed duplication. The elimination of literature duplication was carried out in the form of CiteSpace software and manual verification. First, CiteSpace software is used to deduplicate literature, secondly, two researchers were required to check before and after literature deduplication. These two researchers separately examined the papers by title, abstract, and full text. The searched Web of Science database comes from the Peking University Library database in China.

\section{Analysis Software}

The version of CiteSpace analysis software is 5.2.R1, which was invented by Professor Chen Chaomei from the Computer and Information Science of Drexel University in the United States, and can be used to analyze the structure, laws, and distribution of scientific knowledge. $^{21}$

\section{Download and Import of Data}

The results retrieved by subject words are exported, and the file format is "plain text". The researchers used 
CiteSpace software to remove duplicates and kept a unique record, and then analyzed it.

\section{Parameter Setting}

Time slicing (from 2000 to 2019, years per slice: 2), node type (check one at a time, including Author, Institution, Country, Keyword, Cited Reference), selection criteria (TopN, select top 50 levels of most cited or occurred items from each slice), pruning select Pathfinder, and Pruning the merged network. Because the network obtained by keywords and Cited reference is messy, Therefore, the network screening measures of keywords are as follows: years per slice 3; the keyword analysis should also select pruning sliced networks; and the cited reference analysis also choose pruning sliced networks.

\section{Statistical Methods}

The scientometric analysis was executed on all literature of acupuncture for cancer pain, the frequency of which is mainly utilized to observe the core countries/territories, institutions, authors, cited references, and keywords. Centrality is an indicator to measure the importance of nodes in the network, to discover and measure the significance of the literature. The result of clustering analysis is a keyword co-occurrence network. This network can reflect the current and past research hotspots in a certain field. The cluster view shows the distribution of research fields from different angles. Based on the network structure and the clarity of clustering, CiteSpace provides two indicators: the module value (referred to as $\mathrm{Q}$ value) and the silhouette value (referred to as $\mathrm{S}$ value), as the basis for us to judge the effect of map drawing, the silhouette value is the average that the contour values of each sample point. Generally speaking, the $\mathrm{Q}$ value is generally in the interval $[0,1)$, and $\mathrm{Q}>0.3$ means that the divided community structure is significant; when the $\mathrm{S}$ value is 0.7 , the clustering is highly efficient and convincing, if it is 0.5 above, clustering is generally considered reasonable. ${ }^{22}$ The interpretation of cluster analysis results mainly includes Cluster ID, Mean Year, Size, Silhouette, Label (LLR), and Label (MI). Cluster ID is the number after clustering, and Size represents the number of members contained in the cluster. The larger the Size, the smaller the number. Mean Year represents the average year of the literature in the cluster, which can be used to judge the distance of the cited literature in the cluster. The larger the log-likelihood ratio (LLR), the more representative of the cluster category; mutual information (MI) is mainly used to represent the relationship between terms and categories in text mining, and it does not consider the frequency of feature words. The timeline view mainly shows solicitude for delineating the relationship between clustering results and focuses on the historical span of documents in a clustering result.

\section{Results and Discussion Analysis of the Total Number of \\ Publications}

In Figure 1, we found an interesting phenomenon. 1) 2001-2012: the average annual total number of publications on acupuncture for cancer pain was 14.75 , which was preserved at the same level without any major fluctuations, indicating that acupuncture for cancer pain during this period is developing stably, which can be considered as a stable period. 2) 2013-2016: at this stage, the average annual total number of publications on acupuncture for cancer pain attained 35.25, compared with the previous period, the growth rate is obvious. 3) 2017-2019: in this period, the average annual total number of publications on

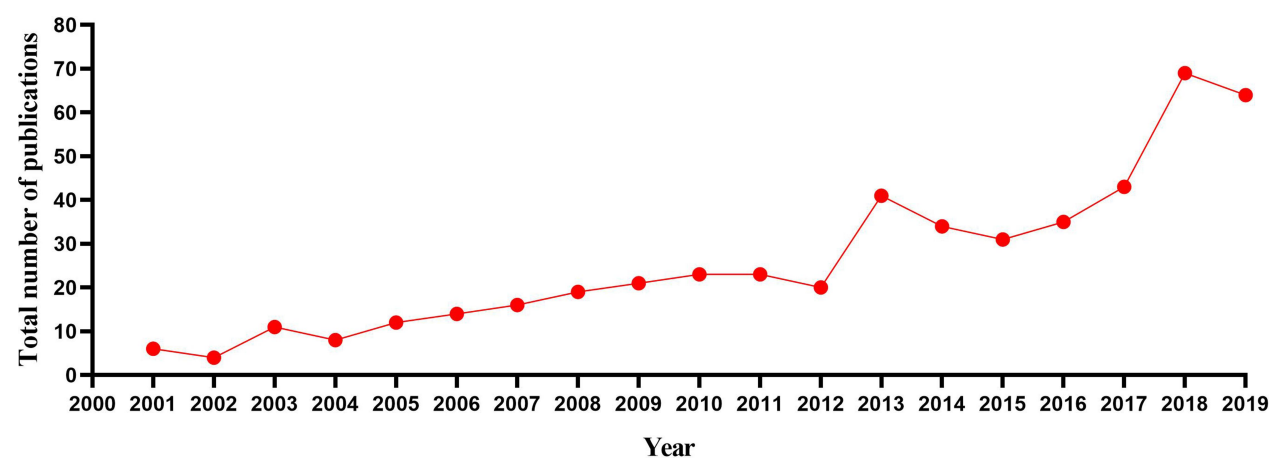

Figure I Line chart of yearly output on acupuncture for cancer pain. The abscissa in the figure represents the year and the ordinate represents the total number of publications. 
acupuncture for cancer pain reached 58.67, compared with the previous two periods, the total number of publications in this period has grown faster. Hence, this period can be named the period of rapid development. Through the comparison of the three, it is found that although the scientific research output of acupuncture for cancer pain has some small fluctuations, the overall development trend is increasing year by year.

\section{Distribution of Countries/Territories/ Institutions and Cluster Analysis}

A network map with 17 nodes and 17 links of countries/ territories was generated (Figure 2), and a cluster map (Modularity $\mathrm{Q}=0.8429$, Silhouette $=0.3774$ ) with 89 nodes and 90 links of institutions emerged, along with timeline view. The countries/territories/institutions that published papers on acupuncture for cancer pain in 2000-2019 are shown in Tables 1 and 2. The most productive country/territories/institutions are the USA (196) and Memorial Sloan Kettering Cancer Center (24), followed by the Peoples Republic of China (102), England (54), South Korea (49), and Germany (28), and the following institutions are Kyung Hee University (22), University of Pennsylvania (14), Columbia University (11), and University of Exeter (10). However, the value of centrality reflects the importance of countries/territories/institutions in the node of the cooperative relationship network, so the most important countries/institutions are Australia

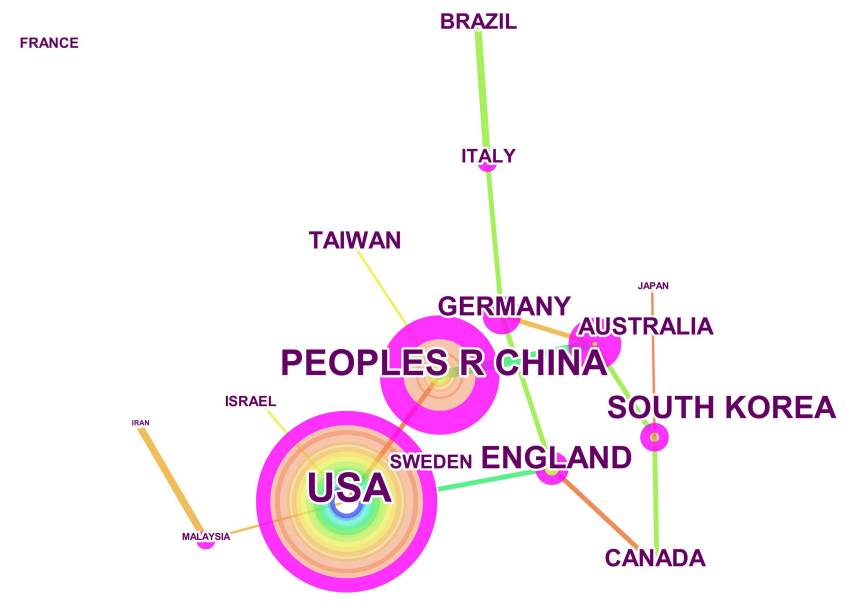

Figure 2 Network of countries/territories on acupuncture for cancer pain. The purple node in the middle of the annual ring means the influence and the significance of a country/territory. The larger the node and the more purple it exhibits, the greater is the importance of the country/territory.

(centrality $=0.90$ ) and University of Maryland (centrality $=0.21)$, followed by Peoples Republic of China (0.82), Germany (0.63), and USA (0.58), and the following institutions are Columbia University (0.20), Kyung Hee University (0.19), and University of Texas Anderson Cancer Center (0.18). We have discovered an interesting phenomenon: both China and South Korea have played a pivotal role in the analysis of the countries'/territories' scientific output or the countries'/territories' importance. The importance of China is not only reflected in the total number of publications and centrality, but also because

Table I Countries/Territories Contributed to Publications on Acupuncture for Cancer Pain from 2000 to 2019

\begin{tabular}{|l|l|l|l|l|}
\hline No. & Country/ TerritoriesFrequency & Frequency & Centrality & Country/ TerritoriesCentrality \\
\hline 1 & USA & 196 & 0.90 & Australia \\
2 & Peoples R China & 102 & 0.82 & Peoples R China \\
3 & England & 54 & 0.63 & Germany \\
4 & South Korea & 49 & 0.58 & USA \\
5 & Germany & 28 & 0.33 & South Korea \\
6 & Taiwan (China) & 22 & 0.27 & England \\
7 & Australia & 19 & 0.22 & Italy \\
8 & Canada & 17 & 0.22 & Malaysia \\
9 & Brazil & 14 & 0.07 & Canada \\
10 & Sweden & 10 & 0.00 & Taiwan (China) \\
11 & Italy & 10 & 0.00 & Brazil \\
12 & France & 6 & 0.00 & Sweden \\
13 & Israel & 5 & 0.00 & France \\
14 & Malaysia & 3 & 0.00 & Israel \\
15 & Japan & 3 & 0.00 & Japan \\
\hline
\end{tabular}

Notes: In this table, the other two identical columns represent different rankings. The left column of the table represents the Countries/ Territories that have published acupuncture treatment for cancer pain. The frequency of contribution is sorted from high to low. The column on the right represents the sorting from high to low according to centrality. 
Table 2 Institutions Contributed to Publications on Acupuncture for Cancer Pain from 2000 to 2019

\begin{tabular}{|l|l|l|l|l|}
\hline No. & InstitutionFrequency & Frequency & Centrality & InstitutionCentrality \\
\hline 1 & Mem Sloan Kettering Canc Ctr & 24 & 0.21 & Univ Maryland \\
2 & Kyung Hee Univ & 22 & 0.20 & Columbia Univ \\
3 & Univ Penn & 14 & 0.19 & Kyung Hee Univ \\
4 & Columbia Univ & 11 & 0.18 & Univ Texas MD Anderson Canc Ctr \\
5 & Univ Exeter & 10 & 0.18 & Pusan Natl Univ \\
6 & Univ Maryland & 10 & 0.16 & Univ Washington \\
7 & Univ Texas MD Anderson Canc Ctr & 9 & 0.10 & Univ Michigan \\
8 & Beijing Univ Chinese Med & 8 & 0.09 & Mem Sloan Kettering Canc Ctr \\
9 & Guangzhou Univ Chinese Med & 8 & 0.09 & Harvard Med Sch \\
10 & China Med Univ & 7 & 0.08 & Korea Inst Oriental Med \\
11 & Univ Washington & 6 & 0.06 & Natl Cheng Kung Univ \\
12 & Harvard Univ & 6 & 0.05 & Univ Pittsburgh \\
13 & Leeds Metropolitan Univ & 6 & 0.04 & Univ Penn \\
14 & Univ Pittsburgh & 6 & 0.04 & Beijing Univ Chinese Med \\
15 & Korea Inst Oriental Med & 6 & 0.04 & China Med Univ \\
\hline
\end{tabular}

Notes: In this table, the two identical columns represent different rankings. The left column of the table represents the country/region that has published acupuncture treatment for cancer pain. The frequency of contribution is sorted from high to low. The column on the right represents the sorting from high to low according to centrality. Abbreviations: Mem Sloan Kettering Canc Ct, Memorial Sloan Kettering Cancer Center; Kyung Hee Uni, Kyung Hee University; Univ Penn, University of Pennsylvania; Columbia Univ, Columbia University; Univ Exeter, University of Exeter; Univ Maryland, University of Maryland; Univ Texas MD Anderson Canc Ctr, University of Texas Anderson Cancer Center; Beijing Univ Chinese Med, Beijing University of Chinese Medicine; Guangzhou Univ Chinese Med, Guangzhou University of Chinese Medicine; China Med Univ, China Medical University; Univ Washington, University of Washington; Harvard Univ, Harvard University; Leeds Metropolitan Univ, Leeds Metropolitan University; Univ Pittsburgh, University of Pittsburgh; Korea Inst Oriental Med, Korea Institute of Oriental Medicine; Pusan Natl Univ, Pusan National University; Univ Michigan, University of Michigan; Harvard Med Sch, Harvard Medical School; Natl Cheng Kung Univ, National Cheng Kung University.

acupuncture originated in China, but the difference is that Chinese scientific institutions are not as important as South Korea in this respect. From the perspective of institutional analysis, the vast majority of institutions are from developed countries, indicating that developed countries are still the world leader in acupuncture for cancer pain, and their cooperation with developing countries is not close. Therefore, developing countries/territories should strengthen cooperation with developed countries/territories and learn from their advanced technologies to promote the development of acupuncture for cancer pain.

Relying on the cluster analysis of institutions, researchers can find the same research category that different institutions are engaged in. This point is mainly based on the cluster view Figure $3 \mathrm{~A}$ and Table 3 . When the cluster view cannot judge which institutions focus on the same research in detail, it will utilize the cluster timeline view Figure 3B to analyze. The whole modularity $\mathrm{Q}=0.8429>0.3$, which indicates that the results of the divided community structure is significant. Four categories were obtained by cluster analysis, which were \#0 nationwide population-based study (Silhouette $=0.975>0.7$, Contains 13 institutions), \#1 publication trend (Silhouette $=0.972>0.7$, Contains 12 institutions), \#2 physical symptom (Silhouette $=0.796>0.7$, Contains 9 institutions), and \#4 breast cancer patient (Silhouette $=0.956>0.7, \quad$ Contains 6 institutions). The

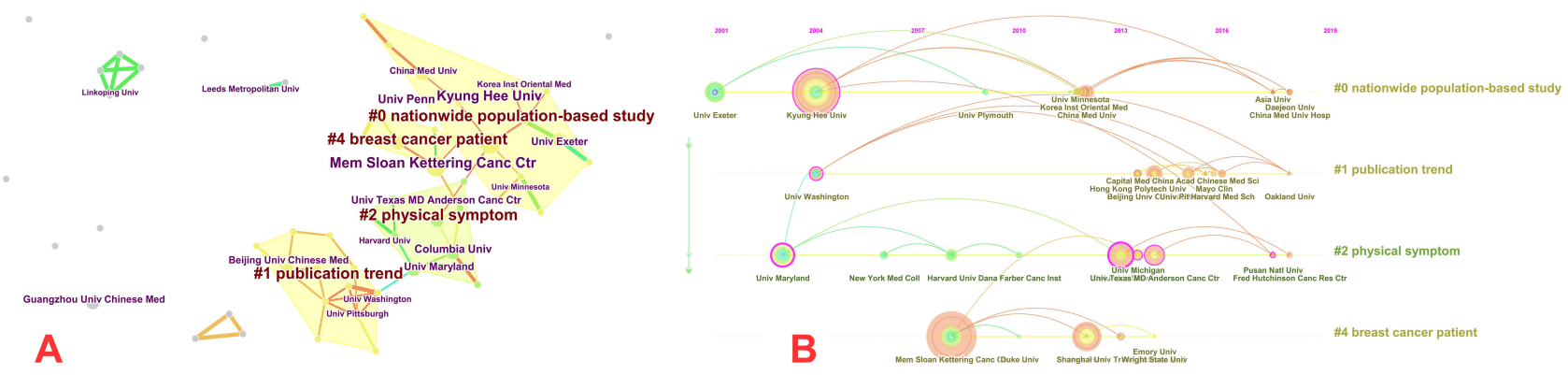

Figure 3 (A) Cluster map of institutions based on label clusters with title terms. The combination of symbols and numbers delegates the institutions' study of similar categories. (B) Timeline zone of institutions on acupuncture for cancer pain. The purple node in the middle of the annual ring means the influence and the significance of the institution. Institutions with the homologous research category are on the same time horizon. 
Table 3 Institutions Engaged in Acupuncture for Cancer Pain That Details of Knowledge Clusters

\begin{tabular}{|l|l|l|l|l|l|}
\hline Cluster-ID & Size & Silhouette & Mean (Year) & Label (LLR) & Label (MI) \\
\hline 0 & 13 & 0.975 & 2012 & nationwide population-based study & chronic pain \\
1 & 12 & 0.972 & 2014 & publication trend & chronic pain \\
2 & 9 & 0.796 & 2011 & physical symptom & international conference \\
4 & 6 & 0.956 & 2011 & breast cancer patient & inhibitor use \\
\hline
\end{tabular}

silhouette of all the clustering results was greater than 0.7 , which indicates that the results of all categories of cluster analysis are very reliable. Combining the results of timeline view and cluster view, it is found that the research direction of institutional cooperation network that Univ Exeter, Kyung Hee Univ, Korea Inst Oriental Med, Natl Cheng Kung Univ, China Med Univ is the nationwide population-based study $(\# 0)$. The relationship network in the category of publication trend (\#1) is a cooperative network between Univ Washington, Beijing Univ Chinese Med, Harvard Med Sch, and Oakland Univ. Furthermore, the earliest research in this direction can be traced back to Univ of Washington 2004. The research direction is the relationship network of the physical symptom (\#2) that the cooperation network between Univ Maryland, Univ Texas MD Anderson Canc Ctr, Columbia Univ, and Pusan Natl Univ. Also, the earliest research in this direction originated from Univ Maryland in 2003. The research direction of the institutional cooperation network of Mem Sloan Kettering Canc Ctr, Univ Penn, Shanghai Univ Tradit Chinese Med, Emory Univ, and Wright State Univ is breast cancer patient (\#4), of which the earliest research on this aspect appeared on 2008 from Mem Sloan Kettering Canc Ctr. It is useful for quickly locating similar studies between institutions and discovering potential cooperation relationships between them. However, the cooperation between institutions is mainly based on institutions in developed countries, and the cooperation between international institutions is also mainly in developed countries. Among them, the institutional cooperation between developing countries and developed countries represented by China is still less, which is the deficiency of this research.

\section{Distribution of Authors and Cluster Analysis}

A cluster map (Figure 4A, Modularity $Q=0.8861$, Silhouette $=0.5277$ ) with 121 nodes and 169 links of authors was emerged by CiteSpace, along with a timeline view (Figure 4B). The distribution of the main scholars engaged in acupuncture for cancer pain is shown in Table 4. Among them, the author with the most published outputs is Mao JJ (17), followed by Ernst E (9), Johnson MI (6), Cassileth BR (6), and Cohen L (6), but from the perspective of centrality, the highest is Bao $\mathrm{T}$ (centrality $=0.09)$, followed by Mao JJ (0.08), Greenlee $\mathrm{H}$ (0.07), Cohen L (0.05) and Piulson L (0.04), therefore, they are considered to be the most important researcher in the Author's network relationship. Then through the cluster analysis, the researcher can quickly locate the same research content and the relationship between different scholars. The results of cluster analysis are shown in Table 5. The modularity $\mathrm{Q}=0.8861>0.3$, which indicates

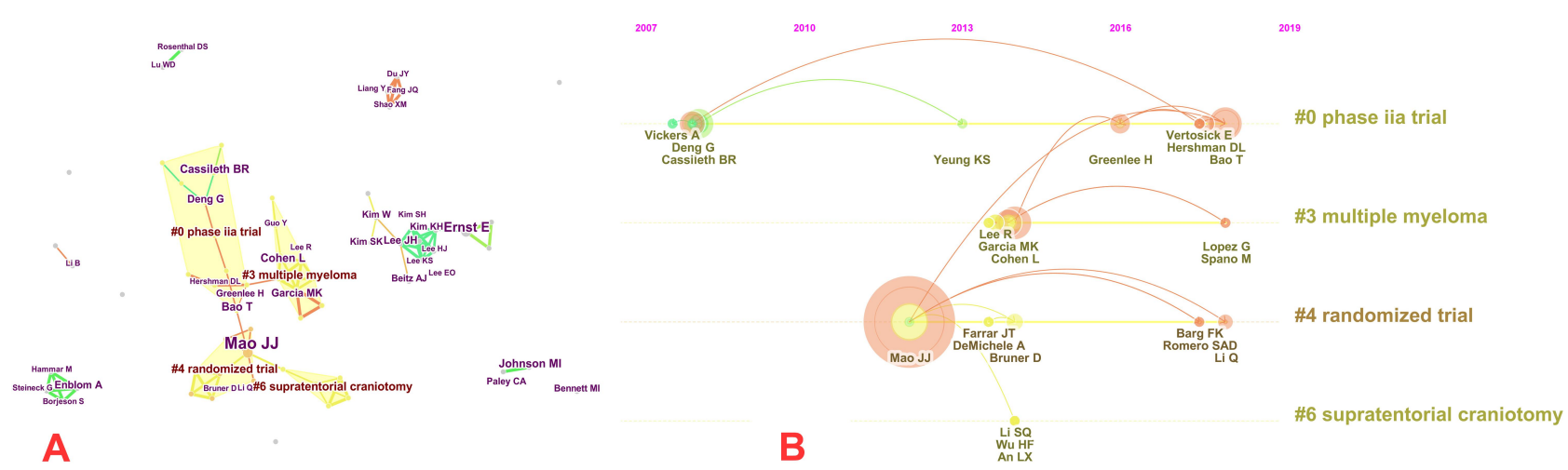

Figure 4 (A) Cluster map of authors based on label clusters with title terms. The combination of symbols and numbers delegates the authors' study of similar categories. (B) Timeline zone of authors on acupuncture for cancer pain. 
Table 4 Authors Contributed to Publications on Acupuncture for Cancer Pain from 2000 to 2019

\begin{tabular}{|l|l|l|l|l|}
\hline No. & AuthorFrequency & Frequency & Centrality & AuthorCentrality \\
\hline $\mathrm{I}$ & Mao JJ & 17 & 0.09 & Bao T \\
2 & Ernst E & 9 & 0.08 & Mao JJ \\
3 & Johnson MI & 6 & 0.07 & Greenlee H \\
4 & Cassileth BR & 6 & 0.05 & Cohen L \\
5 & Cohen L & 6 & 0.04 & Piulson L \\
6 & Bao T & 6 & 0.04 & Vertosick E \\
7 & Deng G & 5 & 0.03 & Deng G \\
8 & Enblom A & 5 & 0.03 & Meghani SH \\
9 & Garcia MK & 5 & 0.02 & Garcia MK \\
10 & Lee JH & 5 & 0.02 & Lee JH \\
$1 \mathrm{I}$ & Paley CA & 4 & 0.02 & Bruner D \\
12 & Greenlee H & 4 & 0.02 & Wei Q \\
13 & Kim W & 4 & 0.02 & Li SQ \\
14 & Bennett MI & 4 & 0.01 & Ernst E \\
I5 & Kim KH & 4 & 0.01 & Cassileth BR \\
\hline
\end{tabular}

Notes: In this table, the other two identical columns represent different rankings. The left column of the table represents the author that has published acupuncture treatment for cancer pain. The frequency of contribution is sorted from high to low. The column on the right represents the sorting from high to low according to centrality.

Table 5 Authors Engaged in Acupuncture for Cancer Pain That Details of Knowledge Clusters

\begin{tabular}{|l|l|l|l|l|l|}
\hline Cluster-ID & Size & Silhouette & Mean (Year) & Label (LLR) & Label (MI) \\
\hline 0 & II & 0.884 & 2013 & phase iia trial & supratentorial craniotomy \\
3 & 9 & 0.990 & 2014 & multiple myeloma & supratentorial craniotomy \\
4 & 8 & 0.943 & 2015 & randomized trial & supratentorial craniotomy \\
6 & 5 & 0.842 & 2014 & supratentorial craniotomy & breast cancer patient \\
\hline
\end{tabular}

that the results of the divided community structure are prominent. Mainly include $\# 0$ phase iia trial (Silhouette $=0.884>0.7$, Contains 11 authors), \#3 multiple myeloma (Silhouette $=0.990>0.7$, Contains 9 authors), \#4 randomized trial (Silhouette $=0.943>0.7$, Contains 8 authors), and \#6 supratentorial craniotomy (Silhouette $=0.842>0.7$, Contains 5 authors). The silhouette of all the clustering results was greater than 0.7 , it points out that all clustering results are credible. Then the following categories are the specific analysis of the same category of the authors. 1) Bao T, Greenlee H, Piulson L, Vertosick E, Deng G and other authors' research on acupuncture for cancer pain can be classified into the same category, namely: phase iia trial (\#0). DengG ${ }^{23}$ randomly divided 162 cancer patients undergoing thoracotomy into an acupuncture group and a control group. However, the results showed that this acupuncture treatment did not reduce the pain of cancer patients after thoracotomy or reduce the use of painkillers. This provides a research method worth learning for acupuncture treatment of postoperative pain after cancer. $\mathrm{Oh} \mathrm{B}^{24}$ randomly divided 32 patients with early breast cancer joint pain into an acupuncture group and a sham acupuncture group. The results of the study showed that acupuncture is feasible and safe for the treatment of breast cancer artificial joint pain. However, due to the lack of clinical samples, it still needs large sample clinical studies to validate these results. These results are very important for the development of evidence-based guidelines on the rational use of acupuncture, so it is possible to safely and effectively integrate acupuncture with traditional medicine in the healthcare system, and Bao T's research ${ }^{25}$ yielded similar results. Bao T's research ${ }^{26}$ focused on the preference of patients with chronic pain form breast cancer for acupuncture and medication and found that breast cancer patients have similar preferences for acupuncture and medication in terms of pain management. These findings have important implications for the design of patient-centered pain management for breast cancer patients. 2) The authors engaged in \#3 multiple myeloma mainly include Cohen L, Garcia MK, Guo Y, Lee R, Li XH, Lopez G, Wei Q, Spano M, and Haddad R.Garcia $\mathrm{MK}^{27}$ used a single-arm non- 
randomized trial to study the treatment of cancer pain with acupuncture and moxibustion. The results showed that acupuncture is feasible, safe, and is a helpful auxiliary treatment for cancer pain patients. Based on outpatient tumor patients, Lopez $\mathrm{G}^{28}$ studied the effects of acupuncture on the self-reported symptoms of tumor patients through retrospective analysis. The results showed that breast cancer is the most common cancer, with more symptoms including pain, and the degree of pain relief by acupuncture is also significant, which indicates that acupuncture treatment has potential benefits in providing clinically significant improvement for common cancerrelated symptoms. 3) Mao JJ, Bruner D, Li Q, Xie SX, Farrar JT, Barg FK, DeMichele A, and Romero SAD concentrated on acupuncture for cancer pain can be classified into \#4 randomized trial. Among this category, Mao $\mathrm{JJ}$ 's research is the most representative. Mao $\mathrm{JJ}^{29}$ conducted semi-structured interviews with stage I-III breast cancer patients to obtain their attitudes and beliefs about acupuncture treatment of hot flashes. The expected treatment effect evaluation included pain relief. The results showed that the evaluation of acupuncture treatment for hot flashes was limited and continuous. Acupuncture may be more in line with some women's preference for natural symptom management methods, thereby minimizing the need for additional drugs. Another study by Mao $\mathrm{JJ}^{30}$ was a randomized controlled trial to observe electroacupuncture treatment of breast cancer patients with aromatase inhibitor-related arthralgia, and the results showed that electroacupuncture showed promise as a treatment for fatigue, sleep, and depression in addition to pain. It shows that combining behavioral tools and biomarkers can help clarify the underlying mechanisms of symptom clusters and acupuncture effects.4) The following authors are included in the \#6 supratentorial craniotomy category: Meghani SH, Ren XJ, Li SQ, Wu HF, and An LX. Through mediating analysis, Meghani $\mathrm{SH}^{31}$ studies the possibility of African American patients with cancer pain to accept analgesics containing toxic metabolites, reduce ethnic differences in opioid prescription types, and understand the mechanism of opioid-related adverse reactions in African American patients, which may reduce the clinical differences related to cancer pain.

The scientific research cooperation network mainly includes authors, countries, and institutions. Through the analysis of their respective relationships, it is first possible to quickly locate scholars engaged in acupuncture for cancer pain, major countries, and key institutions. An intuitive introduction by research scholars also saves a lot of time and cost for them to screen countries, institutions, and author teams that undertook the same research topics. Secondly, their research found that the common shortcoming is that the cooperation between developed countries is relatively close, while the cooperation between developing countries and developed countries is not close enough. For the better development of acupuncture for cancer pain, this deficiency should be improved immediately. China is one of the developing countries, and acupuncture originated in China, while the technical methods or economic foundations of acupuncture for cancer pain in western developed countries are relatively stronger than in China. If the two can strengthen cooperation, the speed of acupuncture for cancer pain will be greatly increased, which will bring good news to patients who suffered cancer pain from all over the world and will also reduce the economic burden on society and save a lot of economic costs.

\section{Distribution of Cited Reference and Cluster Analysis}

The knowledge base and research progress of acupuncture for cancer pain are described using high cocitation references and main article clusters respectively, and the co-citation frequencies of references and their importance in network nodes are shown in Table 6. A cluster map (Figure 5A), (Modularity $\mathrm{Q}=$ 0.8287, Silhouette $=0.4054$ ) with 325 nodes and 625 links of references was generated by CiteSpace, along with a timeline view (Figure 5B). The reference with the highest co-citations is Crew KD $(2010)^{32}$ and Alimi D $(2003)^{33}$ (Frequency=35), followed by Garcia MK (2013) (Frequency=32), Choi TY (2012) (Frequency=31), and Schroeder S (2012) $($ Frequency $=25)$, and the highest centrality is Roscoe JA (2003) (Centrality=0.56) and is regarded as the most important reference in the field, followed by Ho CM (1996) (Centrality=0.54), Dibble SL (2000) $($ Centrality=0.53), Vickers AJ (1996) $($ Centrality=0.53) and Crew KD (2007) (Centrality=0.52). The modularity $\mathrm{Q}>0.3$, which prompts that the results of the divided community structure are conspicuous. For the cluster analysis (Table 7), the fifteen largest clusters (small clusters were automatically filtered), included \#0 palliative cancer care, \#1 acupuncture, \#2 early-stage breast cancer, \#3 randomised clinical trial, \#4 cancer 
Table 6 Cited Reference Contributed to Co-Citations on Acupuncture for Cancer Pain from 2000 to 2019

\begin{tabular}{|c|c|c|c|c|}
\hline No. & Cited ReferenceFrequency & Frequency & Centrality & Cited ReferenceCentrality \\
\hline I & Crew KD $(2010)^{32}$ & 35 & 0.56 & Roscoe JA $(2003)^{63}$ \\
\hline 2 & Alimi D $(2003)^{33}$ & 35 & 0.54 & Ho CM $(1996)^{64}$ \\
\hline 3 & Garcia MK $(2013)^{65}$ & 32 & 0.53 & Dibble SL $(2000)^{66}$ \\
\hline 4 & Choi TY $(2012)^{55}$ & 31 & 0.53 & Vickers AJ $(1996)^{67}$ \\
\hline 5 & Schroeder S $(2012)^{68}$ & 25 & 0.52 & Crew KD $(2007)^{69}$ \\
\hline 6 & Lee $\mathrm{H}(2005)^{70}$ & 24 & 0.39 & Crew KD $(2007)^{71}$ \\
\hline 7 & Donald GK $(20 \mathrm{II})^{72}$ & 22 & 0.39 & Lu W $(2005)^{73}$ \\
\hline 8 & Mao JJ $(20 \mid 4)^{74}$ & 22 & 0.34 & Alimi D $(2003)^{33}$ \\
\hline 9 & Bao T $(2013)^{75}$ & 22 & 0.29 & Oh B $(2013)^{24}$ \\
\hline 10 & Vickers AJ $(2012)^{76}$ & 21 & 0.27 & Bao T $(2013)^{75}$ \\
\hline 11 & Hershman DL $(2014)^{77}$ & 19 & 0.27 & Mehling WE $(2007)^{78}$ \\
\hline 12 & Paley CA $(2015)^{57}$ & 18 & 0.21 & Gorin SS $(2012)^{37}$ \\
\hline 13 & Shen JN $(2000)^{79}$ & 17 & 0.21 & Ezzo JM $(2006)^{80}$ \\
\hline 14 & Molassiotis A $(2012)^{39}$ & 15 & 0.20 & Molassiotis A $(2005)^{81}$ \\
\hline 15 & Vickers AJ $(2004)^{45}$ & 15 & 0.18 & Streitberger K $(2003)^{82}$ \\
\hline
\end{tabular}

Notes: In this table, the other two identical columns represent different rankings. The left column of the table represents the cited references that have published acupuncture treatment for cancer pain. The frequency of contribution is sorted from high to low. The column on the right represents the sorting from high to low according to centrality.

care, \#5 clinical oncology program multicenter study, \#6 comprehensive pain care, \#7 cancer-induced bone pain, \#8 cancer symptom management, \#9 acupuncture use, \#10 chemotherapy-induced peripheral neuropathy, \#11 symptom management, \#12 psychosocial aspect, \#13 placebo effect, and \#14 neck malignancies. The silhouette of all the clustering results was greater than 0.7, which indicates that all clustering results are dependable. 1) Cancer nursing research: mainly includes \#0 palliative cancer care, \#4 cancer care, and \#6 comprehensive pain care. The interventions involved include not only acupuncture, ${ }^{34}$ but also yoga $^{35}$ (yoga has strong benefits for distress, anxiety, and depression, has a moderate effect on social and psychological functions and has no significant effect on physical functions and sleep disorders), massage therapy $^{36}$ (massage therapy can reduce the symptoms of cancer patients by about $50 \%$; it can not only improve blood and lymph flow, reduce muscle tone, increase pain threshold, lower blood pressure, but also improve mood and relax the spirit), psychosocial intervention $^{37}$ (psychosocial intervention has a moderate effect on the severity of pain, and it can be used as part of a multimodal approach to pain
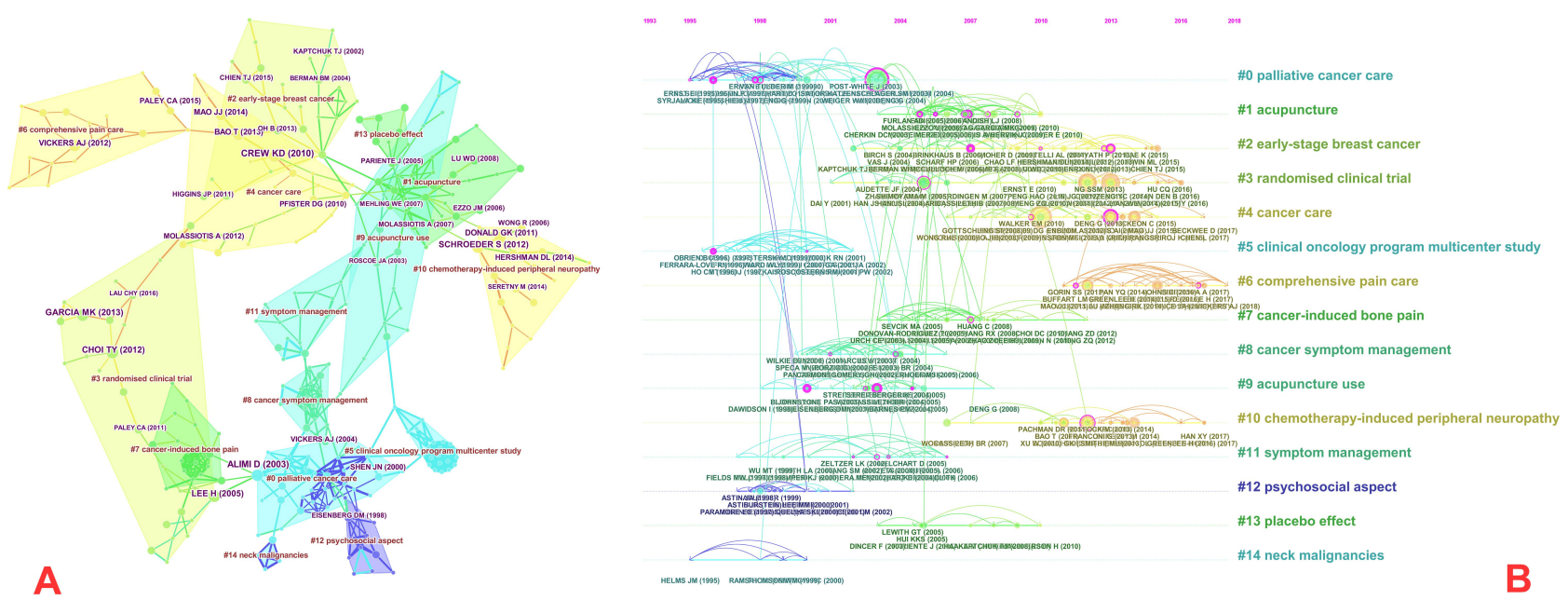

Figure 5 (A) Cluster map of cited reference based on label clusters with title terms. The combination of symbols and numbers delegates the cited references' study of similar categories. (B) Timeline zone of cited reference on acupuncture for cancer pain. 
Table 7 Cited Reference Engaged in Acupuncture for Cancer Pain That Details of Knowledge Clusters

\begin{tabular}{|l|l|l|l|l|l|}
\hline Cluster-ID & Size & Silhouette & Mean (Year) & Label (LLR) & Label (MI) \\
\hline 0 & 32 & 0.815 & 1999 & palliative cancer care & neck malignancies \\
1 & 29 & 0.893 & 2006 & acupuncture & neck malignancies \\
2 & 27 & 0.950 & 2009 & early-stage breast cancer & neck malignancies \\
3 & 26 & 0.904 & 2009 & randomised clinical trial & neck malignancies \\
4 & 24 & 0.935 & 2011 & cancer care & neck malignancies \\
5 & 22 & 0.977 & 1999 & clinical oncology program multicenter study & neck malignancies \\
6 & 21 & 0.979 & 2015 & comprehensive pain care & neck malignancies \\
7 & 19 & 0.980 & 2007 & cancer-induced bone pain & neck malignancies \\
8 & 18 & 0.958 & 2002 & cancer symptom management & neck malignancies \\
9 & 18 & 0.795 & 2003 & acupuncture use & neck malignancies \\
10 & 18 & 0.960 & 2012 & chemotherapy-induced peripheral neuropathy & bortezomib-induced peripheral neuropathy \\
11 & 17 & 0.949 & 2002 & symptom management & symptom management \\
12 & 12 & 0.953 & 1999 & psychosocial aspect & psychosocial aspect \\
13 & 8 & 0.991 & 2006 & placebo effect & acupuncture \\
14 & 4 & 0.990 & 1998 & neck malignancies & acupuncture \\
\hline
\end{tabular}

management in cancer patients), etc. In addition to cancer pain intervention, it also includes cancer radiation xerostomia, ${ }^{38}$ the fatigue of breast cancer patients, $^{39}$ vasomotor symptoms of breast cancer patients, ${ }^{40}$ and nausea and vomiting caused by delayed chemotherapy in patients with gynecological cancer, ${ }^{41}$ these are all important parts of this category. 2) Symptom management of cancer: mainly includes two aspects of \#8 cancer symptom management and \#11 symptom management. The symptoms involved include not only pain but also emotional stress symptoms, ${ }^{42}$ quality of life, ${ }^{43}$ dyspnea, nausea, vomiting, ${ }^{44}$ and fatigue, ${ }^{45}$ etc. The treatment methods included are not limited to acupuncture, it also includes interactive music therapy ${ }^{46}$ (music therapy has a calming and pleasant effect on many hospitalized cancer children; interactive music therapy can reduce the anxiety of cancer hospitalized children and increase their positive emotions), hypnosis and cognitive behavioral training ${ }^{47}$ (cognitive behavior can improve patient compliance, reduce economic costs, save time allocation, and minimize children's pain and anxiety), acupoint injection ${ }^{48}$ (neiguan acupoint injection has the same effect as droperidol on the control of early postoperative nausea and vomiting in children), Reiki therapy ${ }^{49}$ (Reiki therapy is a method of utilizing cosmic energy to cure diseases, maintain health, and cultivate; and it is recognized as the simplest, most efficient, most convenient and best energy therapy system in the world of natural medicine), mindfulness meditation ${ }^{50}$ (mindfulness meditation can effectively reduce overall mood disorders and specific symptoms of anxiety, depression, anger, and confusion in patients with various cancers), etc., which are the main research content of this category. Regarding the treatment of cancer pain with acupuncture, the treatment methods involved and other related symptoms have been analyzed in other categories, so we will not repeat them here. 3) Types of diseases treated by acupuncture: including \#2 early breast cancer, \#7 bone pain caused by cancer, \#10 chemotherapy-induced peripheral neuropathy, \#14 neck malignancies, etc. The research on early breast cancer is based on acupuncture treatment of aromatase inhibitor-related arthralgia representative. Bone pain caused by cancer: Zhang $\mathrm{RX}^{51}$ studied the therapeutic effects of electroacupuncture on bone cancer pain. The results showed that electroacupuncture can reduce the pain of bone cancer by inhibiting the expression of interleukin-1 $\beta$. The results support the clinical application of electroacupuncture in the treatment of cancer pain. Chemotherapy-induced peripheral neuropathy: this peripheral neuropathy is mostly caused by chemotherapy for breast cancer or multiple myeloma. A retrospective case study $^{52}$ was conducted on the efficacy of acupuncture and reflex therapy in alleviating the symptoms of peripheral neuropathy in patients with breast cancer. $93 \%$ of the patients were effectively relieved, indicating that this therapy can be used as a preventive treatment. Han XY's research ${ }^{53}$ concen- $^{2}$ trates on the combined treatment of acupuncture and 
mecobalamin for peripheral neuropathy caused by chemotherapy in multiple myeloma. 104 patients were randomly divided into a mecobalamin treatment group and acupuncture combined mecobalamin treatment group. After treatment, it was found that acupuncture combined therapy has obvious advantages in pain relief and improvement of quality of life, suggesting that acupuncture is a safe and effective treatment method. Neck malignancies: Johnstone PAS ${ }^{54}$ intervened with acupuncture on 18 patients with xerostomia who did not respond to pilocarpine treatment due to malignant tumors of the head and neck after radiotherapy. The results showed that this therapy increased the flow rate of saliva, and acupuncture using ear and finger points helped temporarily relieve xerostomia in some patients with refractory symptoms after radiotherapy.4) \#3 randomised clinical trial: Choi $\mathrm{TY}^{55}$ conducted a systematic review of all randomized controlled trials of acupuncture for the treatment of cancer pain. The results showed that all RCT studies originated from China, and the accuracy of the results is open to question. Moreover, the total number of randomized controlled trials included in the analysis and their methodological quality is too low, and the quality of randomized controlled trials needs to be improved to obtain definite conclusions. Randomized trial studies on acupuncture also involve multicenter studies of acupuncture and the placebo effect of acupuncture treatment, which have greatly enriched the research content of cancer pain treatment.

\section{Distribution of Keywords and Cluster Analysis}

Table 8 shows keywords contributed to publications on acupuncture for cancer pain. The top five keywords are acupuncture (Frequency=290), pain (161), cancer (97), quality of life (92), and management (91). But from the perspective of centrality, the most vital keyword in the network is auricular acupuncture (centrality $=0.35$ ), followed by alternative medicine (centrality $=0.30)$, complementary $(0.24)$, palliative care $(0.21)$, and chemotherapy induced nausea (centrality $=0.21$ ). Figure 6A and Table 9 exhibit keyword co-occurrence cluster analysis, a knowledge mapping with 191 nodes and 317 keywords links and cluster view (Figure 6B), modular $\mathrm{Q}=0.7353$, Mean silhouette $=0.7291$ are created. The modularity $\mathrm{Q}>0.3$, which indicates that the results of the divided community structure are remarkable. The timeline view shows that new keywords appear almost every year. In the cluster map, the

Table 8 Keyword Contributed to Publications on Acupuncture for Cancer Pain from 2000 to 2019

\begin{tabular}{|c|c|c|c|c|}
\hline No. & KeywordFrequency & Frequency & Centrality & KeywordCentrality \\
\hline I & acupuncture & 290 & 0.35 & auricular acupuncture \\
\hline 2 & pain & 161 & 0.30 & alternative medicine \\
\hline 3 & cancer & 97 & 0.24 & complementary \\
\hline 4 & quality of life & 92 & 0.21 & palliative care \\
\hline 5 & management & 91 & 0.21 & chemotherapy induced nausea \\
\hline 6 & breast cancer & 82 & 0.21 & acupuncture treatment \\
\hline 7 & electroacupuncture & 75 & 0.16 & quality \\
\hline 8 & randomized controlled trial & 53 & 0.15 & pain \\
\hline 9 & therapy & 52 & 0.15 & neuropathic pain \\
\hline 10 & alternative medicine & 46 & 0.14 & complementary therapy \\
\hline 11 & complementary & 43 & 0.13 & quality of life \\
\hline 12 & chemotherapy & 43 & 0.12 & cancer pain \\
\hline 13 & women & 37 & 0.12 & expression \\
\hline 14 & low back pain & 32 & 0.12 & adult \\
\hline 15 & controlled trial & 32 & 0.12 & hypnosis \\
\hline 16 & acupressure & 32 & 0.11 & prevalence \\
\hline 17 & nausea & 31 & 0.11 & integrative medicine \\
\hline 18 & prevalence & 30 & 0.11 & complementary medicine \\
\hline 19 & neuropathic pain & 30 & 0.11 & oncology \\
\hline 20 & cancer pain & 29 & 0.11 & xerostomia \\
\hline
\end{tabular}

Notes: In this table, the other two identical columns represent different rankings. The left column of the table represents keywords that have published acupuncture treatment for cancer pain. The frequency of contribution is sorted from high to low. The column on the right represents the sorting from high to low according to centrality. 

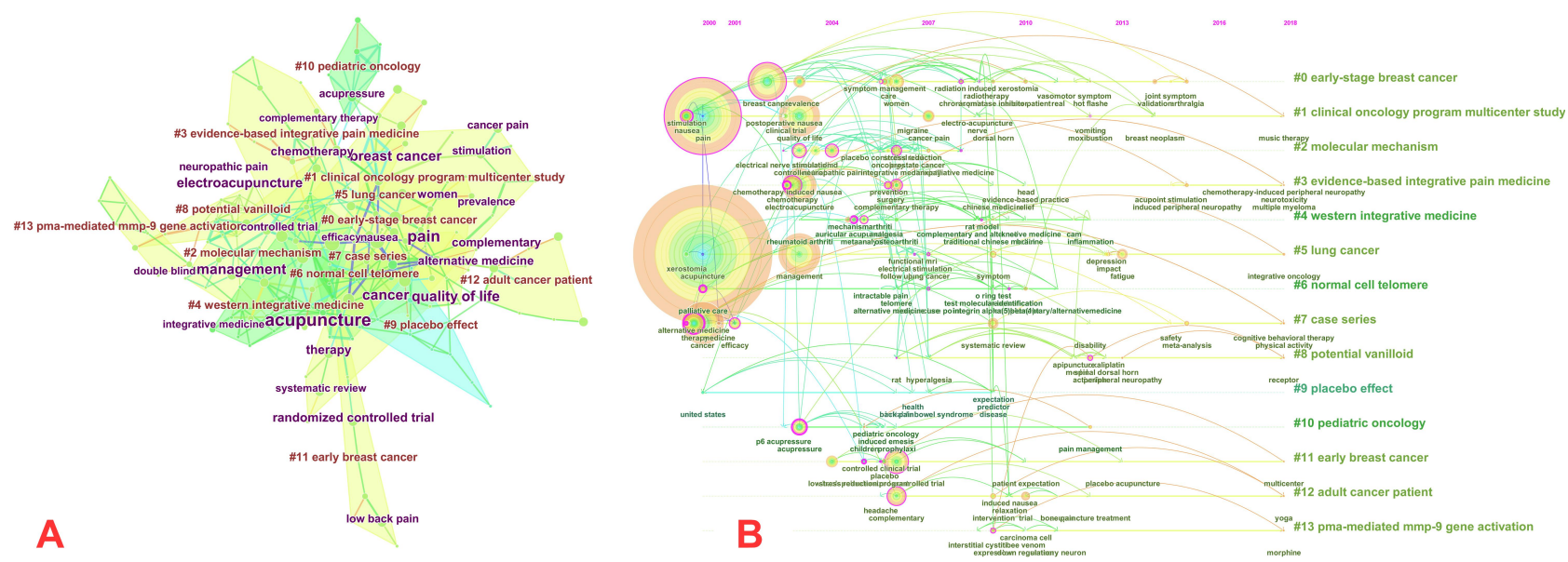

Figure 6 (A) Cluster map of keyword based on label clusters with title terms. The combination of symbols and numbers delegates the keywords' study of similar categories. (B) Timeline zone of keyword on acupuncture for cancer pain.

fourteen largest clusters (small clusters were automatically filtered), contained \#0 early-stage breast cancer, \#1 clinical oncology program multicenter study, \#2 molecular mechanism, \#3 evidence-based integrative pain medicine, \#4 western integrative medicine, \#5 lung cancer, \#6 normal cell telomere, \#7 case series, \#8 potential vanilloid, \#9 placebo effect, \#10 pediatric oncology, \#11 early breast cancer, \#12 adult cancer patient, and \#13 PMA-mediated MMP-9 gene activation. The silhouette of all the clustering results was greater than 0.5 , it states clearly that all clustering results are authentic. Through the frequency and centrality analysis of keywords, it is found that the types of diseases involved include breast cancer pain, vomiting, insomnia caused by cancer chemotherapy, and neuropathic pain caused by cancer. The patterns of the first two and the cluster analysis of references showed a similar pattern, and the neuropathic pain caused by cancer is new emerging research. Ching-Feng $\mathrm{Su}^{56}$ found that acupuncture is a safe, cheap, effective, simple, and minimally invasive treatment method with no serious side effects through a case report of acupuncture treatment of cancer bone metastasis neuropathic pain, but this method cannot provide definite evidence. To prove its effectiveness, rigorous randomized clinical trials are needed for in-depth analysis. The cluster analysis of keywords found that the research population of cancer pain involves adults and children. Among them, Paley CA's research ${ }^{57}$ analyzes the efficacy of acupuncture in alleviating cancer-related pain in adults. Compared with drugs, acupuncture and acupoint injection can alleviate pain for a long time. However, due to methods, small sample size, insufficient analysis, and other reasons, there is not enough evidence to judge whether

Table 9 Keywords Engaged in Acupuncture for Cancer Pain That Details of Knowledge Clusters

\begin{tabular}{|l|l|l|l|l|l|}
\hline Cluster-ID & Size & Silhouette & Mean (Year) & Label (LLR) & Label (MI) \\
\hline 0 & 22 & 0.765 & 2008 & early-stage breast cancer & oral cancer pain \\
1 & 19 & 0.807 & 2006 & clinical oncology program multicenter study & oral cancer pain \\
2 & 18 & 0.682 & 2005 & molecular mechanism & oral cancer pain \\
3 & 18 & 0.797 & 2009 & evidence-based integrative pain medicine & oral cancer pain \\
4 & 17 & 0.762 & 2007 & western integrative medicine & oral cancer pain \\
5 & 13 & 0.802 & 2007 & lung cancer & oral cancer pain \\
6 & 13 & 0.808 & 2007 & normal cell telomere & oral cancer pain \\
7 & 13 & 0.840 & 2006 & case series & integrative treatment \\
8 & 11 & 0.795 & 2011 & potential vanilloid & oral cancer pain \\
9 & 11 & 0.856 & 2007 & placebo effect & lung cancer \\
10 & 9 & 0.949 & 2005 & pediatric oncology & lung cancer \\
11 & 9 & 0.923 & 2008 & early breast cancer & oral cancer pain \\
12 & 9 & 0.937 & 2010 & adult cancer patient & oral cancer pain \\
13 & 7 & 0.944 & 2011 & PMA-mediated MMP-9 gene activation & lung cancer \\
\hline
\end{tabular}


acupuncture is effective in treating adult cancer pain. DeMoss Patrick's study ${ }^{58}$ explored the therapeutic effects of acupuncture from the perspective of amputation pain in children with bone tumors and found that comprehensive treatment methods such as psychotherapy and acupuncture may have the best effect before and immediately after amputation. Besides, the result of cluster analysis also includes the following aspects. 1) \#5 lung cancer: Nobel $\mathrm{S}^{59}$ took lung cancer as an example to study the role of acupuncture in pain management after thoracotomy. The data show that acupuncture can reduce the pain after thoracotomy, and it is well-tolerated, and the limitation of movement caused by pain is restored. 2) \#7 case series: to seek complementary and alternative medicines to manage cancerrelated symptoms or side effects of treatment, Vinjamury $\mathrm{SP}^{60}$ evaluated the feasibility of acupuncture for cancer pain through case studies. The results showed that acupuncture may improve the symptoms of cancer pain and improve the quality of life of patients. It provides a methodological basis for exploring a preliminary plan for acupuncture treatment of cancer pain. 3) \#8 potential vanilloid: the most representative study in this category is the effect of ST36 (Zusanli) acupoint electroacupuncture on Walker 256 tumor-bearing rats with cancer pain and transient receptor potential vanilloid subfamily 1 expression. ${ }^{61}$ By observing the electroacupuncture treatment by internal injection of Walker 256 cancer cells and dorsal root ganglion (DRGs) tumor-driven TRPV1 expression induced cancer pain effect, Zusanli plays an analgesic effect by inhibiting the up-regulation of TRPV1 gene and protein in DRGs, which is the mechanism of acupuncture treatment of cancer pain research provides experimental basis. 4) \#13 PMAmediated MMP-9 gene activation: The most important research in this category is bee venom suppresses PMAmediated MMP-9 gene activation via JNK/p38 and NF-kBdependent mechanisms. ${ }^{62}$ The results show that bee venom suppresses through p38 MAPK and JNK signaling pathways in MCF-7 cells. NF-kB inhibits the expression and activity of MMP-9 induced by PMA, thereby exerting anti-cancer and anti-metastasis mechanisms. This not only provides new treatment methods for cancer treatment but also provides ideas for the analysis of anti-cancer mechanisms.

\section{Research Limitations}

There are two limitations to this study. Firstly, although the search strategy searches for synonyms of the MeSH subject words in PubMed, it may still cause some pieces of literature to be missed. Secondly, CiteSpace's function of removing duplication has certain limitations, which may bias the research results. It is just an analysis of the Web of
Science database, which may not fully represent the overall trend. In addition, because some literature will be published online in advance, it will cause the inconsistency between the collection date and the publication date of this literature, so the criteria we include need to be further improved.

\section{Conclusions}

In this paper, we used CiteSpace to conduct scientometric analysis on acupuncture for cancer pain in the Web of Science database, and acquired the knowledge mapping of countries, institutions, authors, keywords, and cited references in this field. This study provides a new perspective on the trend of acupuncture for cancer pain. Although this study has some limitations, it fully reveals the global trend of acupuncture for cancer pain. The overall trend of publications has increased from 6 published papers in 2001 to 64 published papers in 2019, and the trend is increasing year by year. Developed countries have contributed the most, but the contributions of China and South Korea also occupy the forefront. The vital reference is Roscoe JA published in 2003 with the title The Efficacy of Acupressure and Acustimulation Wrist Bands for the Relief of Chemotherapy-Induced Nausea and Vomiting A University of Rochester Cancer Center Community Clinical Oncology Program Multicenter Study. And the most convincing research topic is breast cancer. Comparing the $\mathrm{S}$ values of different cluster categories, we found that the research category with the largest $\mathrm{S}$ value is early breast cancer, cancer-induced bone pain, and the placebo effect. Therefore, it is regarded as the most reliable research and is the hotspot of research.

All in all, the results of this study may provide researchers with useful information, such as research frontiers, potential collaborators and cooperative institutions, important research content, and key references.

\section{Acknowledgments}

The authors would like to express their appreciation to Professor Chaomei Chen for inventing CiteSpace and making it free to use.

\section{Author Contributions}

Li Huang designed this study. Li Huang performed the search. Yan-qing Zhao collected data. Li Huang and Yan-qing Zhao rechecked data. Yan-qing Zhao and Li Huang performed analysis. Li Huang and Min-hong Xiang critically revised the work. Yan-qing Zhao and Li Huang have contributed 
equally to this work and should be considered co-first authors. All authors made substantial contributions to conception and design, acquisition of data, or analysis and interpretation of data; took part in drafting the article or revising it critically for important intellectual content; agreed to submit to the current journal; gave final approval of the version to be published; and agree to be accountable for all aspects of the work.

\section{Funding}

This study was supported by grants from the National Natural Science Foundation of China (no. 82,074,495), Budget Project of Shanghai University of Chinese Medicine (no. 2019WK118), and Scientific Research Project of Putuo Hospital, Shanghai University of Traditional Chinese Medicine (No.2020304A).

\section{Disclosure}

The authors report no conflicts of interest in this work.

\section{References}

1. Torre LA, Bray F, Siegel RL, et al. Global cancer statistics, 2012. $C A$ Cancer J Clin. 2015;65:87-108. doi:10.3322/caac.21262

2. He Y, Guo X, May BH, et al. Clinical evidence for association of acupuncture and acupressure with improved cancer pain: a systematic review and meta-analysis. Jama Oncol. 2020;6:271-278. doi:10.1001/jamaoncol.2019.5233

3. Paice JA, Ferrell B. The management of cancer pain. CA Cancer J Clin. 2011;61:157-182. doi:10.3322/caac.20112

4. Can G, Mushani T, Rajhi B, et al. The global burden of cancer pain. Semin Oncol Nurs. 2019;35:315-321. doi:10.1016/j. soncn.2019.04.014

5. Ventafridda V, Saita L, Ripamonti C, et al. WHO guidelines for the use of analgesics in cancer pain. Int J Tissue React. 1985;7:93-96.

6. Chiu HY, Hsieh YJ, Tsai PS. Systematic review and meta-analysis of acupuncture to reduce cancer-related pain. Eur J Cancer Care (Engl). 2017;26:26. doi:10.1111/ecc.12457

7. Ng JY, Sharma AE. Guidelines for cancer-related pain: a systematic review of complementary and alternative medicine recommendations. Pain Pract. 2020. doi:10.1111/papr.12964

8. Badenhorst A, Mansoori P, Chan KY. Assessing global, regional, national and sub-national capacity for public health research: a bibliometric analysis of the web of science (TM) in 1996-2010. $J$ Glob Health. 2016;6:10504. doi:10.7189/jogh.06.010504

9. Wang Z, Chen Y, Cai G, et al. A bibliometric analysis of pubmed literature on middle east respiratory syndrome. Int J Environ Res Public Health. 2016;13.

10. Chen Q, Li Y, Wang X, et al. Hot topics in global perianal fistula research: A scopus-based bibliometric analysis. Medicine. 2020;99: e19659. doi:10.1097/MD.0000000000019659

11. Machado-Silva A, Guindalini C, Fonseca FL, et al. Scientific and technological contributions of Latin America and Caribbean countries to the Zika virus outbreak. BMC Public Health. 2019;19:530. doi:10.1186/s12889-019-6842-X

12. Guo S, Wang L, Xie Y, et al. Bibliometric and visualized analysis of stem cells therapy for spinal cord injury based on web of science and citespace in the last 20 years. World Neurosurg. 2019;132:e246-58. doi:10.1016/j.wneu.2019.08.191
13. Xie L, Chen Z, Wang H, et al. Bibliometric and visualized analysis of scientific publications on atlantoaxial spine surgery based on web of science and VOSviewer. World Neurosurg. 2020;137:435-442. doi:10.1016/j.wneu.2020.01.171

14. Bornmann L, Marx W. HistCite analysis of papers constituting the h index research front. $J$ Informetr. 2012;6:285-288. doi:10.1016/j. joi.2011.11.001

15. Yin $\mathrm{M}, \mathrm{Xu} \mathrm{C}, \mathrm{Ma} \mathrm{J}$, et al. A bibliometric analysis and visualization of current research trends in the treatment of cervical spondylotic myelopathy. Global Spine J. 2020;301242720.

16. Chen C. Searching for intellectual turning points: progressive knowledge domain visualization. Proc Natl Acad Sci U S A. 2004;101 (Suppl 1):5303-5310. doi:10.1073/pnas.0307513100

17. Chen C, Dubin R, Kim MC. Emerging trends and new developments in regenerative medicine: a scientometric update (2000-2014). Expert Opin Biol Ther. 2014;14:1295-1317. doi:10.1517/14712598.2 014.920813

18. Caomei C. CiteSpace II: detecting and visualizing emerging trends and transient patterns in scientific literature. J Am Society Information Sci Technol. 2006;57:359-377. doi:10.1002/asi.20317

19. Zhao Y, Huang L, Xiang M, et al. Trends in conjunctivochalasis research from 1986 to 2017: A bibliometric analysis. Medicine. 2018;97:e12643. doi:10.1097/MD.0000000000012643

20. Zhou S, Tao Z, Zhu Y, et al. Mapping theme trends and recognizing hot spots in postmenopausal osteoporosis research: a bibliometric analysis. PEER J. 2019;7:e8145. doi:10.7717/peerj.8145

21. Wang SQ, Gao YQ, Zhang C, et al. A bibliometric analysis using citespace of publications from 1999 to 2018 on patient rehabilitation after total knee arthroplasty. Med Sci Monit. 2020;26:e920795. doi:10.12659/MSM.920795

22. Miao Y, Liu R, Pu Y, et al. Trends in esophageal and esophagogastric junction cancer research from 2007 to 2016: A bibliometric analysis. Medicine. 2017;96:e6924. doi:10.1097/MD.0000000000006924

23. Deng G, Rusch V, Vickers A, et al. Randomized controlled trial of a special acupuncture technique for pain after thoracotomy. $J$ Thorac Cardiovasc Surg. 2008;136:1464-1469. doi:10.1016/j.jtcvs.2008.07.053

24. Oh B, Kimble B, Costa DS, et al. Acupuncture for treatment of arthralgia secondary to aromatase inhibitor therapy in women with early breast cancer: pilot study. Acupunct Med. 2013;31:264-271. doi:10.1136/acupmed-2012-010309

25. Bao T, Seidman AD, Piulson L, et al. A phase IIA trial of acupuncture to reduce chemotherapy-induced peripheral neuropathy severity during neoadjuvant or adjuvant weekly paclitaxel chemotherapy in breast cancer patients. Eur J Cancer. 2018;101:12-19. doi:10.1016/j. ejca.2018.06.008

26. Bao T, Li SQ, Dearing JL, et al. Acupuncture versus medication for pain management: a cross-sectional study of breast cancer survivors. Acupunct Med. 2018;36:80-87. doi:10.1136/acupmed-2017-011435

27. Garcia MK, Driver L, Haddad R, et al. Acupuncture for treatment of uncontrolled pain in cancer patients: a pragmatic pilot study. Integr Cancer Ther. 2014;13:133-140. doi:10.1177/1534735413510558

28. Lopez G, Garcia MK, Liu W, et al. Outpatient acupuncture effects on patient self-reported symptoms in oncology care: a retrospective analysis. J Cancer. 2018;9:3613-3619. doi:10.7150/jca.26527

29. Mao JJ, Leed R, Bowman MA, et al. Acupuncture for hot flashes: decision making by breast cancer survivors. J Am Board Fam Med. 2012;25:323-332. doi:10.3122/jabfm.2012.03.110165

30. Mao JJ, Farrar JT, Bruner D, et al. Electroacupuncture for fatigue, sleep, and psychological distress in breast cancer patients with aromatase inhibitor-related arthralgia: a randomized trial. Cancer-Am Cancer Soc. 2014;120:3744-3751.

31. Meghani SH, Kang Y, Chittams J, et al. African Americans with cancer pain are more likely to receive an analgesic with toxic metabolite despite clinical risks: a mediation analysis study. J Clin Oncol. 2014;32:2773-2779. doi:10.1200/JCO.2013.54.7992 
32. Crew KD, Capodice JL, Greenlee H, et al. Randomized, blinded, sham-controlled trial of acupuncture for the management of aromatase inhibitor-associated joint symptoms in women with early-stage breast cancer. J Clin Oncol. 2010;28:1154-1160. doi:10.1200/ JCO.2009.23.4708

33. Alimi D, Rubino C, Pichard-Leandri E, et al. Analgesic effect of auricular acupuncture for cancer pain: a randomized, blinded, controlled trial. J Clin Oncol. 2003;21:4120-4126. doi:10.1200/JCO.2003.09.011

34. Lu W, Rosenthal DS. Acupuncture for cancer pain and related symptoms. Curr Pain Headache Rep. 2013;17:321. doi:10.1007/ s11916-013-0321-3

35. Buffart LM, van Uffelen JG, Riphagen II, et al. Physical and psychosocial benefits of yoga in cancer patients and survivors, a systematic review and meta-analysis of randomized controlled trials. BMC CANCER. 2012;12:559. doi:10.1186/1471-2407-12-559

36. Lee SH, Kim JY, Yeo S, et al. Meta-analysis of massage therapy on cancer pain. Integr Cancer Ther. 2015;14:297-304. doi:10.1177/ 1534735415572885

37. Gorin S, Krebs P, Badr H, et al. Meta-analysis of psychosocial interventions to reduce pain in patients with cancer. J Clin Oncol. 2012;30:539-547. doi:10.1200/JCO.2011.37.0437

38. Cho JH, Chung WK, Kang W, et al. Manual acupuncture improved quality of life in cancer patients with radiation-induced xerostomia. J Altern Complement Med. 2008;14:523-526. doi:10.1089/acm.2007.0793

39. Molassiotis A, Bardy J, Finnegan-John J, et al. Acupuncture for cancer-related fatigue in patients with breast cancer: a pragmatic randomized controlled trial. J Clin Oncol. 2012;30:4470-4476. doi:10.1200/JCO.2012.41.6222

40. Walker EM, Rodriguez AI, Kohn B, et al. Acupuncture versus venlafaxine for the management of vasomotor symptoms in patients with hormone receptor-positive breast cancer: a randomized controlled trial. J Clin Oncol. 2010;28:634-640. doi:10.1200/JCO.2009.23.5150

41. Rithirangsriroj K, Manchana T, Akkayagorn L. Efficacy of acupuncture in prevention of delayed chemotherapy induced nausea and vomiting in gynecologic cancer patients. Gynecol Oncol. 2015;136:82-86. doi:10.1016/j.ygyno.2014.10.025

42. Speca M, Carlson LE, Goodey E, et al. A randomized, wait-list controlled clinical trial: the effect of a mindfulness meditation-based stress reduction program on mood and symptoms of stress in cancer outpatients. Psychosom Med. 2000;62:613-622. doi:10.1097/00006842-200009000-00004

43. Carlson LE, Speca M, Patel KD, et al. Mindfulness-based stress reduction in relation to quality of life, mood, symptoms of stress, and immune parameters in breast and prostate cancer outpatients. Psychosom Med. 2003;65:571-581. doi:10.1097/01.PSY.0000074003.35911.41

44. Pan CX, Morrison RS, Ness J, et al. Complementary and alternative medicine in the management of pain, dyspnea, and nausea and vomiting near the end of life. A systematic review. J Pain Symptom Manage. 2000;20:374-387. doi:10.1016/S0885-3924(00)00190-1

45. Vickers AJ, Straus DJ, Fearon B, et al. Acupuncture for postchemotherapy fatigue: a Phase II study. $J$ Clin Oncol. 2004;22:1731-1735. doi:10.1200/JCO.2004.04.102

46. Barrera ME, Rykov MH, Doyle SL. The effects of interactive music therapy on hospitalized children with cancer: a pilot study. Psychooncology. 2002;11:379-388. doi:10.1002/pon.589

47. Liossi C, Hatira P. Clinical hypnosis versus cognitive behavioral training for pain management with pediatric cancer patients undergoing bone marrow aspirations. Int $J$ Clin Exp Hypn. 1999;47:104-116. doi:10.1080/00207149908410025

48. Wang SM, Kain ZN. P6 acupoint injections are as effective as droperidol in controlling early postoperative nausea and vomiting in children. Anesthesiology. 2002;97:359-366. doi:10.1097/00000542200208000-00012

49. Olson K, Hanson J, Michaud M. A phase II trial of Reiki for the management of pain in advanced cancer patients. J Pain Symptom Manage. 2003;26:990-997. doi:10.1016/S0885-3924(03)00334-8
50. Carlson LE, Ursuliak Z, Goodey E, et al. The effects of a mindfulness meditation-based stress reduction program on mood and symptoms of stress in cancer outpatients: 6-month follow-up. Support Care Cancer. 2001;9:112-123. doi:10.1007/s005200000206

51. Zhang RX, Li A, Liu B, et al. Electroacupuncture attenuates bone cancer pain and inhibits spinal interleukin-1 beta expression in a rat model. Anesth Analg. 2007;105:1482-1488. doi:10.1213/01. ane.0000284705.34629.c5

52. Ben-Horin I, Kahan P, Ryvo L, et al. Acupuncture and reflexology for chemotherapy-induced peripheral neuropathy in breast cancer. Integr Cancer Ther. 2017;16:258-262. doi:10.1177/1534735417690254

53. Han X, Wang L, Shi H, et al. Acupuncture combined with methylcobalamin for the treatment of chemotherapy-induced peripheral neuropathy in patients with multiple myeloma. BMC Cancer. 2017;17:40. doi:10.1186/s12885-016-3037-z

54. Johnstone PA, Peng YP, May BC, et al. Acupuncture for pilocarpine-resistant xerostomia following radiotherapy for head and neck malignancies. Int $J$ Radiat Oncol Biol Phys. 2001;50:353-357. doi:10.1016/S0360-3016(00)01530-3

55. Choi TY, Lee MS, Kim TH, et al. Acupuncture for the treatment of cancer pain: a systematic review of randomised clinical trials. Support Care Cancer. 2012;20:1147-1158. doi:10.1007/s00520-012-1432-9

56. $\mathrm{Su} \mathrm{CF}$. Home care with acupuncture increased the quality of life in a patient with advanced cancer with neuropathic pain induced by bone metastasis: a case report. J Integr Med. 2018;16:208-210. doi:10.1016/j.joim.2018.04.003

57. Paley CA, Johnson MI, Tashani OA, et al. Acupuncture for cancer pain in adults. Cochrane Database Syst Rev. 2015;D7753.

58. DeMoss P, Ramsey LH, Karlson CW. Phantom limb pain in pediatric oncology. Front Neurol. 2018;9:219. doi:10.3389/ fneur.2018.00219

59. Noble S, Williamson IJ, Brewster AE, Ionescu AA, Kulatilake N. The role of acupuncture in the management of post-thoracotomy pain: description and evaluation of an acupuncture service in lung cancer survivorship. Lung Cancer. 2013;79:S39-40. doi:10.1016/ S0169-5002(13)70114-4

60. Vinjamury SP, Li JT, Hsiao E, et al. Effects of acupuncture for cancer pain and quality of life - a case series. Chin Med. 2013;8:15. doi:10.1186/1749-8546-8-15

61. Zhang Z, Wang $\mathrm{C}, \mathrm{Gu} \mathrm{G}$, et al. The effects of electroacupuncture at the ST36 (Zusanli) acupoint on cancer pain and transient receptor potential vanilloid subfamily 1 expression in Walker 256 tumor-bearing rats. Anesth Analg. 2012;114:879-885. doi:10.1213/ ANE.0b013e318246536d

62. Cho HJ, Jeong YJ, Park KK, et al. Bee venom suppresses PMA-mediated MMP-9 gene activation via JNK/p38 and NF-kappaB-dependent mechanisms. $J$ Ethnopharmacol. 2010;127:662-668. doi:10.1016/j.jep.2009.12.007

63. Roscoe JA, Morrow GR, Hickok JT, et al. The efficacy of acupressure and acustimulation wrist bands for the relief of chemotherapy-induced nausea and vomiting. A University of rochester cancer center community clinical oncology program multicenter study. J Pain Symptom Manage. 2003;26:731-742. doi:10.1016/ S0885-3924(03)00254-9

64. Ho CM, Hseu SS, Tsai SK, et al. Effect of P-6 acupressure on prevention of nausea and vomiting after epidural morphine for post-cesarean section pain relief. Acta Anaesthesiol Scand. 1996;40:372-375. doi:10.1111/j.1399-6576.1996.tb04448.x

65. Garcia MK, McQuade J, Haddad R, et al. Systematic review of acupuncture in cancer care: a synthesis of the evidence. J Clin Oncol. 2013;31:952-960. doi:10.1200/JCO.2012.43.5818

66. Dodd MJ, Dibble SL, Miaskowski C, et al. Randomized clinical trial of the effectiveness of 3 commonly used mouthwashes to treat chemotherapy-induced mucositis. Oral Surg Oral Med Oral Pathol Oral Radiol Endod. 2000;90:39-47. doi:10.1067/ moe.2000.105713 
67. Vickers AJ. Can acupuncture have specific effects on health? A systematic review of acupuncture antiemesis trials. J R Soc Med. 1996;89:303-311. doi:10.1177/014107689608900602

68. Schroeder S, Meyer-Hamme G, Epplee S. Acupuncture for chemotherapy-induced peripheral neuropathy (CIPN): a pilot study using neurography. Acupunct Med. 2012;30:4-7. doi:10.1136/ acupmed-2011-010034

69. Crew KD, Greenlee H, Capodice J, et al. Prevalence of joint symptoms in postmenopausal women taking aromatase inhibitors for early-stage breast cancer. J Clin Oncol. 2007;25:3877-3883. doi:10.1200/JCO.2007.10.7573

70. Lee H, Schmidt K, Ernst E. Acupuncture for the relief of cancerrelated pain-a systematic review. Eur J Pain. 2005;9:437-444. doi:10.1016/j.ejpain.2004.10.004

71. Crew KD, Neugut AI, Wang X, et al. Racial disparities in treatment and survival of male breast cancer. $J$ Clin Oncol. 2007;25:1089-1098. doi:10.1200/JCO.2006.09.1710

72. Donald GK, Tobin I, Stringer J. Evaluation of acupuncture in the management of chemotherapy-induced peripheral neuropathy. Acupunct Med. 2011;29:230-233. doi:10.1136/acupmed.2011.010025

73. Lu W, Parikh PJ, El NI, et al. Quantitation of the reconstruction quality of a four-dimensional computed tomography process for lung cancer patients. Med Phys. 2005;32:890-901. doi:10.1118/ 1.1870152

74. Mao JJ, Xie SX, Farrar JT, et al. A randomised trial of electro-acupuncture for arthralgia related to aromatase inhibitor use. Eur J Cancer. 2014;50:267-276. doi:10.1016/j.ejca.2013.09.022

75. Bao T, Cai L, Giles JT, et al. A dual-center randomized controlled double blind trial assessing the effect of acupuncture in reducing musculoskeletal symptoms in breast cancer patients taking aromatase inhibitors. Breast Cancer Res Treat. 2013;138:167-174. doi:10.1007/ s10549-013-2427-z
76. Vickers AJ, Cronin AM, Maschino AC, et al. Acupuncture for chronic pain: individual patient data meta-analysis. Arch Intern Med. 2012;172:1444-1453. doi:10.1001/archinternmed.2012.3654

77. Hershman DL, Lacchetti C, Dworkin RH, et al. Prevention and management of chemotherapy-induced peripheral neuropathy in survivors of adult cancers: american society of clinical oncology clinical practice guideline. J Clin Oncol. 2014;32:1941-1967. doi:10.1200/ JCO.2013.54.0914

78. Mehling WE, Jacobs B, Acree M, et al. Symptom management with massage and acupuncture in postoperative cancer patients: a randomized controlled trial. $J$ Pain Symptom Manage. 2007;33:258-266. doi:10.1016/j.jpainsymman.2006.09.016

79. Shen J, Wenger N, Glaspy J, et al. Electroacupuncture for control of myeloablative chemotherapy-induced emesis: A randomized controlled trial. JAMA. 2000;284:2755-2761. doi:10.1001/ jama.284.21.2755

80. Ezzo JM, Richardson MA, Vickers A, et al. Acupuncture-point stimulation for chemotherapy-induced nausea or vomiting. Cochrane Database Syst Rev. 2006;D2285.

81. Molassiotis A, Fernandez-Ortega P, Pud D, et al. Use of complementary and alternative medicine in cancer patients: a European survey. Ann Oncol. 2005;16:655-663. doi:10.1093/annonc/mdi110

82. Streitberger K, Friedrich-Rust M, Bardenheuer H, et al. Effect of acupuncture compared with placebo-acupuncture at P6 as additional antiemetic prophylaxis in high-dose chemotherapy and autologous peripheral blood stem cell transplantation: a randomized controlled single-blind trial. Clin Cancer Res. 2003;9:2538-2544.

\section{Publish your work in this journal}

The Journal of Pain Research is an international, peer reviewed, open access, online journal that welcomes laboratory and clinical findings in the fields of pain research and the prevention and management of pain. Original research, reviews, symposium reports, hypothesis formation and commentaries are all considered for publication. The manuscript management system is completely online and includes a very quick and fair peer-review system, which is all easy to use. Visit http:// www.dovepress.com/testimonials.php to read real quotes from published authors. 